\title{
Medidas de audição de pais de indivíduos com deficiência auditiva de herança autossômica recessiva*****
}

\author{
Auditory measurements in parents of individuals with autosomal \\ recessive hearing loss
}

\author{
Larissa Suyama da Silva* \\ Regina Célia Mingroni Netto** \\ Seisse Gabriela Gandolfi Sanches*** \\ Renata Mota Mamede Carvallo****
}

\author{
*Fonoaudióloga. Aprimoranda em \\ Neuro-Geriatria em Fonoaudiologia \\ pelo Hospital das Clínicas da \\ Faculdade de Medicina da \\ Universidade de São Paulo (HC - \\ FMUSP). Endereço para \\ correspondência: Av. D. Pedro II, 1963 \\ - Rancharia - SP - CEP 19600-000 \\ (larissa.suyama.silva@usp.br). \\ **Bióloga. Doutora em Biologia \\ (Genética) pela USP. Professora \\ Assistente do Departamento de \\ Genética e Biologia Evolutiva do \\ Instituto de Biociências da USP. \\ ***Fonoaudióloga do Departamento \\ de Fisioterapia, Fonoaudiologia e \\ Terapia Ocupacional da FMUSP. \\ Doutora em Ciências pela FMUSP. \\ ****Fonoaudióloga. Livre-Docente do \\ Curso de Fonoaudiologia da FMUSP. \\ Professora Associada do Departamento \\ de Fisioterapia, Fonoaudiologia e \\ Terapia Ocupacional da FMUSP. \\ *****Trabalho Realizado no \\ Departamento de Fisioterapia, \\ Fonoaudiologia e Terapia Ocupacional \\ da FMUSP.
}

Artigo Original de Pesquisa

Artigo Submetido a Avaliação por Pares

Conflito de Interesse: não

\begin{abstract}
Background: audiological evaluation of parents of individuals with autosomal recessive hearing loss. Aim: to study the audiological profile of parents of individuals with autosomal recessive hearing loss, inferred by family history or by molecular tests that detected heterozygous mutations in the GJB2 gene. This gene codes Connexin 26. Method: participants were 36 subjects, ranging between 30 and 60 years, who were divided into two groups: a control group composed by individuals without auditory complaints and without family history of hearing loss, and a research group composed by heterozygous parents of individuals with autosomal recessive hearing loss or heterozygous for connexin 26 mutations. All subjects underwent pure tone audiometry (0,25 to $8 \mathrm{kHz}$ ), high frequencies audiometry (9 to $20 \mathrm{kHz}$ ) and distortion product otoacoustic emissions (DPOAE). Results: there were significant differences between the groups when considering the amplitude of DPOAE in the frequencies of 1001 and $1501 \mathrm{~Hz}$. Amplitude was higher in the control group. There was no significant difference between the groups for pure tone thresholds from 0.25 to $20 \mathrm{KHz}$. Conclusion: the DPOAE were more effective, in comparison to the pure tone audiometry, to detect auditory differences between the groups. More studies of this type are necessary to confirm the observed results.
\end{abstract}

Key Words: Deafness; Audiometry; Spontaneous Otoacoustic Emissions.

\section{Resumo}

Tema: avaliação audiológica de pais de indivíduos com perda auditiva de herança autossômica recessiva. Objetivo: estudar o perfil audiológico de pais de indivíduos com perda auditiva, de herança autossômica recessiva, inferida pela história familial ou por testes moleculares que detectaram mutação no gene GJB2, responsável por codificar a Conexina 26. Método: 36 indivíduos entre 30 e 60 anos foram avaliados e divididos em dois grupos: grupo controle, sem queixas auditivas e sem história familiar de deficiência auditiva, e grupo de estudos composto por pais heterozigotos em relação a genes de surdez de herança autossômica recessiva inespecífica ou portadores heterozigotos de mutação no gene da Conexina 26. Todos foram submetidos à audiometria tonal liminar $(0,25 \mathrm{kHz}$ a 8$)$, audiometria de altas freqüências $(9 \mathrm{kHz}$ a 20$)$ e emissões otoacústicas produtos de distorção (EOAPD). Resultados: houve diferenças significativas na amplitude das EOAPD nas freqüências 1001 e $1501 \mathrm{~Hz}$ entre os grupos, sendo maior a amplitude no grupo controle. Não houve diferença significativa entre os grupos para os limiares tonais de 0,25 a 20KHz. Conclusão: as EOAPD foram mais eficazes, em comparação com a audiometria tonal liminar, para detectar diferenças auditivas entre os grupos. Mais pesquisas são necessárias para verificar a confiabilidade destes dados.

Palavras-Chave: Surdez; Audiometria; Emissões Otoacústicas Espontâneas. 


\section{Introdução}

A deficiência auditiva de origem genética é altamente heterogênea e suas bases são complexas. A surdez hereditária pode ser classificada em sindrômica (30\% dos casos), quando co-ocorre com várias outras alterações (dificuldades de aprendizagem, distúrbios intelectuais, distúrbios atencionais, distúrbios visuais, entre outras) ${ }^{1}$. A surdez não-sindrômica, que corresponde a cerca de $70 \%$ dos casos, pode apresentar os padrões de herança do tipo autossômico recessivo, autossômico dominante, ligado ao X e mitocondrial².

Em torno de $80 \%$ das deficiências auditivas hereditárias não-sindrômicas apresentam padrão de herança autossômico recessivo ${ }^{3}$. A perda auditiva de herança recessiva écausada por combinação, no mesmo indivíduo, de duas mutações recessivas alélicas, ou seja, no mesmo gene ou, até mesmo, em alguns casos excepcionais, em diferentes genes do mesmo grupo de funções ${ }^{4}$. Acredita-se que $1 \%$ dos genes humanos possa estar envolvido no processo da audição ${ }^{5}$.

As formas de herança autossômica recessiva são geralmente mais severas, causadas quase que exclusivamente por defeitos cocleares ${ }^{6}$. Neste padrão de herança, os pais do sujeito com deficiência auditiva são portadores, em heterozigose, de um alelo recessivo que causa a surdez e, em teoria, são assintomáticos.

As mutações no loco DFNB1, na região cromossômica 13q11-12, são responsáveis por cerca de metade dos casos de perda auditiva autossômica recessiva ${ }^{7}$ e caracterizadas por conferir um quadro, na maioria dos casos, congênito, tipicamente nãoprogressivo e de grau moderado a profundo. Este loco contém dois genes, GJB2 e GJB6. O primeiro codifica a Conexina $26^{8}$ e o segundo, a Conexina $30^{9}$.

No gene GJB2 ocorrem muitas mutações que conferem quadros de surdez de herança autossômica recessiva. A grande expressão das conexinas na cóclea demonstra sua importância para o processo da audição ${ }^{10}$. A mutação c.35delG é a deleção de uma base guanina, dentre seis guaninas, no nucleotídeo 35 do gene que codifica a Conexina 26 e resulta numa interrupção prematura de sua tradução ${ }^{11}$. É a mutação mais frequentemente encontrada entre pacientes com surdez hereditária, principalmente nas populações de origem mediterrânea européia, estadunidense e, em recente estudo, também na população de São Paulo, etnicamente miscigenada ${ }^{12}$.

O estudo das medidas de audição nos pais destes sujeitos poderia ser de utilidade na identificação de alterações auditivas discretas. Essa caracterização poderia, no futuro, vir a indicar nas famílias quais indivíduos poderiam ser portadores de alelos recessivos que causam surdez, principalmente nos casos em que ainda não há testes moleculares disponíveis.
O objetivo desta pesquisa é avaliar o perfil audiológico de pais de sujeitos com deficiência auditiva de herança autossômica recessiva, inferida pela genealogia ou comprovada em testes moleculares que detectaram mutações no gene GJB2.

\section{Método}

Todos os sujeitos desta pesquisa confirmaram sua anuência através de assinatura do Termo de Consentimento Livre e Esclarecido, aprovado pelo Comitê de Ética para Análise de Projetos de Pesquisa - CAPPesq - do Hospital das Clínicas da Faculdade de Medicina da Universidade de São Paulo (FMUSP), protocolo número 0581/08, em 06 de agosto de 2008.

Esta pesquisa foi conduzida no Laboratório de Investigação Fonoaudiológica em Audição Humana do Curso de Fonoaudiologia da FMUSP, de setembro de 2008 a dezembro de 2009.

Participaram desta pesquisa 36 indivíduos na faixa etária de 30 a 60 anos, que compuseram dois diferentes grupos:

Grupo Pesquisa (GP): 14 sujeitos, pais e mães de pelo menos um indivíduo com surdez de herança autossômica recessiva. Os filhos possuíam surdez geralmente pré-lingual de moderada à profunda. Os critérios de inclusão foram: pais consanguíneos (com ao menos um filho com deficiência auditiva), pais assintomáticos com mais de um filho com surdez ou indivíduos com mutações no gene da Conexina 26 (GJB2) em heterozigose, detectadas por meio de testes moleculares.

Todos os indivíduos com deficiência auditiva, filhos dos pais selecionados para participar do grupo Pesquisa, foram estudados previamente em relação às principais mutações responsáveis por surdez hereditária. A mutação c. 35delG no gene da Conexina 26 (GJB2) foi estudada por meio da reação em cadeia da polimerase (PCR), seguida de digestão do DNA com enzima de restrição BstN $\mathrm{I}^{13}$. A mutação c.167delT no gene da Conexina 26 (GJB2) foi estudada por meio da reação em cadeia da polimerase (PCR), seguida de digestão do DNA com enzima de restrição PstI ${ }^{14}$. As mutações do tipo deleção, chamadas de $\Delta$ (GJB6-D13S1830) e $\Delta$ (GJB6-D13S1854) no gene da Conexina 30 (GJB6) foram estudadas por meio da reação em cadeia da polimerase (PCR) específica para detectar essas deleções ${ }^{15}$. A mutação A1555G no gene da subunidade $12 \mathrm{~S}$ do ribossomo (MTRNR1) foi estudada por meio da reação em cadeia da polimerase (PCR) seguida de digestão do DNA com enzima de restrição Hae III $^{16}$.

No caso dos indivíduos com surdez em que foram detectadas mutações nos genes da 
Conexina 26 ou 30, seus pais foram igualmente testados para verificar se eram portadores de mutações em heterozigose. Assim, nove indivíduos do grupo de pesquisa eram pais de indivíduos que mostraram resultados normais nos testes moleculares (surdez autossômica recessiva sem diagnóstico molecular) e cinco indivíduos do grupo pesquisa eram pais de indivíduos com 35delG em homozigose e, portanto, eram portadores de 35delG em heterozigose.

A distribuição por faixa etária foi: 4 sujeitos de 30 a 40 anos, 6 sujeitos de 40 a 50 anos e 4 sujeitos de 50 a 60 anos.

Grupo Controle (GC): 22 sujeitos, pais e mães de indivíduos sem perda auditiva e sem história familiar de deficiência auditiva. A distribuição por faixa etária foi: 10 sujeitos de 30 a 40 anos, 5 sujeitos de 40 a 50 anos e 7 sujeitos de 50 a 60 anos.

Os critérios de exclusão foram: presença de perda auditiva adquirida; história de exposição a ruído de intensidade elevada, sem uso de equipamento individual de proteção; consumo de álcool ou drogas e presença de transtorno pigmentar do tipo vitiligo.

Cada participante foi submetido à: timpanometria na modalidade de Admitância Compensada na altura da Membrana Timpânica (Ymt) com frequência de sonda de $226 \mathrm{~Hz}$; pesquisas de reflexos acústicos com estímulos de $500 \mathrm{~Hz}, 1000 \mathrm{~Hz}, 2000 \mathrm{~Hz}, 4000 \mathrm{~Hz}$ e ruído de Faixa Larga (Broad Band Noise), na modalidade ipsilateral; audiometria tonal de 250 a $20000 \mathrm{~Hz}$.

A timpanometria e a pesquisa dos reflexos acústicos foram necessárias para que fossem eliminados os casos de comprometimento da orelha média, não incluídos nesta pesquisa.
Foram adotados os critérios específicos de normalidade para audiometria convencional ${ }^{17} \mathrm{e}$ uma padronização para audiometria em altas frequências ${ }^{18}$.

Foram empregados o teste estatístico paramétrico $t$-Student para amostras pareadas e o teste não-paramétrico de Mann-Whitney, com os recursos do Software Minitab versão 15.1. O nível de significância adotado foi de $5 \%$.

\section{Resultados}

Quatro sujeitos do Grupo Pesquisa (todos os sujeitos na faixa etária de 50 a 60 anos deste grupo) apresentaram perda de audição e, devido a este fato, não foram submetidos à avaliação das emissões otoacústicas e limiares de frequências ultra-altas.

Foi utilizado o teste $t$ - Student para amostras pareadas para verificar o efeito de orelha nas frequências da audiometria. Verificou-se que houve efeito de orelha apenas para a frequência de $9 \mathrm{kHz}$, cuja análise não foi então incluída nesta pesquisa.

Como não houve efeito de orelha para as frequências incluídas, foram calculadas as médias dos limiares auditivos para orelhas direita e esquerda dos indivíduos do grupo controle e do grupo pesquisa de 10 a $20 \mathrm{kHz}$, para que pudessem ser comparadas aos resultados das emissões otoacústicas - produto de distorção.

Em relação à audiometria convencional e de frequências ultra-altas, os dados audiológicos encontram-se, respectivamente, nas Tabelas 1 e 2.

TABELA 1. Resultados da análise intergrupos para a audiometria tonal.

\begin{tabular}{|c|c|c|c|c|c|c|}
\hline Frequência (Hz) & Grupo & Média & Mediana & $\mathrm{DP}$ & P-Valor (Mann-Whitney) & P-Valor (Teste-t) \\
\hline \multirow[t]{2}{*}{250} & GP & 7,75 & 7,50 & 5,83 & \multirow{2}{*}{0,2373} & \multirow{2}{*}{0,213} \\
\hline & GC & 5,119 & 5,000 & 3,577 & & \\
\hline \multirow[t]{2}{*}{500} & GP & 7,5 & 5,00 & 7,07 & \multirow{2}{*}{0,4020} & \multirow{2}{*}{0,329} \\
\hline & GC & 5,00 & 4,74 & 4,74 & & \\
\hline \multirow[t]{2}{*}{1000} & GP & 8,75 & 7,50 & 7,00 & \multirow{2}{*}{0,1844} & \multirow{2}{*}{0,168} \\
\hline & GC & 5,238 & 5,000 & 4,176 & & \\
\hline \multirow[t]{2}{*}{2000} & GP & 7,25 & 3,75 & 8,37 & \multirow{2}{*}{0,7952} & \multirow{2}{*}{0,447} \\
\hline & GC & 5,00 & 5,00 & 5,00 & & \\
\hline \multirow[t]{2}{*}{3000} & GP & 8,75 & 6,25 & 7,00 & \multirow{2}{*}{0,1845} & \multirow{2}{*}{0,182} \\
\hline & GC & 5,24 & 5,00 & 5,24 & & \\
\hline \multirow[t]{2}{*}{4000} & GP & 8,75 & 8,75 & 6,80 & \multirow{2}{*}{0,2744} & \multirow{2}{*}{0,241} \\
\hline & GC & 5,83 & 5,00 & 4,63 & & \\
\hline \multirow[t]{2}{*}{6000} & GP & 14,75 & 16,25 & 7,21 & \multirow{2}{*}{0,1075} & \multirow{2}{*}{0,116} \\
\hline & GC & 10,595 & 10,000 & 3,945 & & \\
\hline \multirow[t]{2}{*}{8000} & GP & 11,75 & 12,50 & 6,67 & \multirow{2}{*}{0,7165} & \multirow{2}{*}{0,687} \\
\hline & GC & 10,71 & 10,00 & 6,38 & & \\
\hline
\end{tabular}

Legenda: GC: grupo controle; GP: grupo pesquisa. 
Em relação às emissões otoacústicas - produto de distorção, foi feita uma média da taxa sinal-ruído (SNR) dos sujeitos de cada grupo. Os resultados estão na Tabela 3.

Verifica-se, através dos valores marcados com asterisco, que houve significância estatística para as frequências de 1001 e $1501 \mathrm{~Hz}$.

Por meio da realização do teste $t$ - Student para amostras pareadas e teste de Mann-Whitney, não foi possível verificar diferenças estatisticamente significantes $(\mathrm{p}<0,05)$ entre os dois grupos, tanto para os limiares da audiometria de frequências ultra-altas, como para as emissões otoacústicas - produto de distorção, exceto nas frequências de $1001 \mathrm{e} 1501 \mathrm{~Hz}$ nas EOAPD. No entanto, os limiares audiométricos dos sujeitos do grupo controle mostraram-se aumentados em relação ao grupo pesquisa (exceto para a frequência de $20000 \mathrm{~Hz}$ ) e as amplitudes das EOAPD mostraram-se menores no grupo pesquisa em relação ao grupo controle, sugerindo ligeira vantagem, em relação às medidas de audição, nos sujeitos não-portadores de alelo mutado.

TABELA 2. Resultados da análise intergrupos para a audiometria de freqüências ultra-altas.

\begin{tabular}{|c|c|c|c|c|c|c|}
\hline Frequência (Hz) & Grupo & Média & Mediana & DP & P-Valor (Mann-Whitney) & P-Valor (Teste-t) \\
\hline \multirow{2}{*}{10000} & GP & 19,25 & 20,00 & 12,25 & \multirow{2}{*}{0,4838} & \multirow{2}{*}{0,626} \\
\hline & GC & 16,79 & 15,00 & 14,36 & & \\
\hline \multirow{2}{*}{11200} & GP & 28,25 & 22,50 & 20,17 & \multirow{2}{*}{0,2187} & \multirow{2}{*}{0,245} \\
\hline & GC & 19,29 & 15,00 & 17,20 & & \\
\hline \multirow{2}{*}{12500} & GP & 30,25 & 30,00 & 26,63 & \multirow{2}{*}{0,8489} & \multirow{2}{*}{0,741} \\
\hline & GC & 27,02 & 30,00 & 20,88 & & \\
\hline \multirow{2}{*}{14000} & GP & 41,75 & 36,25 & 21,51 & \multirow{2}{*}{0,7506} & \multirow{2}{*}{0,759} \\
\hline & GC & 39,05 & 42,50 & 24,73 & & \\
\hline \multirow{2}{*}{16000} & GP & 45,25 & 51,25 & 12,72 & \multirow{2}{*}{0,3086} & \multirow{2}{*}{0,231} \\
\hline & GC & 38,10 & 45,00 & 19,35 & & \\
\hline \multirow{2}{*}{18000} & GP & 25,75 & 27,50 & 7,82 & \multirow{2}{*}{0,6551} & \multirow{2}{*}{0,503} \\
\hline & GC & 23,45 & 27,50 & 10,53 & & \\
\hline \multirow{2}{*}{20000} & GP & 4,25 & 3,73 & 3,92 & \multirow{2}{*}{0,4366} & \multirow{2}{*}{0,300} \\
\hline & GC & 6,07 & 5,00 & 5,45 & & \\
\hline
\end{tabular}

Legenda: GC - grupo controle; GP - grupo pesquisa.

TABELA 3. Resultados da análise intergrupos para as emissões otoacústicas.

\begin{tabular}{|c|c|c|c|c|c|c|}
\hline Frequência (Hz) & Grupo & Média & Mediana & $\mathrm{DP}$ & P-Valor (Mann-hitney) & P-Valor (Teste-t) \\
\hline 1001 & $\begin{array}{l}\text { GP } \\
\text { GC }\end{array}$ & $\begin{array}{l}13,24 \\
18,79\end{array}$ & $\begin{array}{l}12,95 \\
19,65\end{array}$ & $\begin{array}{l}6,54 \\
7,41\end{array}$ & $0,0447^{*}$ & $0,047^{*}$ \\
\hline 1501 & $\begin{array}{l}\text { GP } \\
\text { GC }\end{array}$ & $\begin{array}{l}13,60 \\
21,20\end{array}$ & $\begin{array}{l}14,25 \\
22,25\end{array}$ & $\begin{array}{l}4,17 \\
5,61\end{array}$ & $0,0013^{*}$ & $0,000 *$ \\
\hline 2002 & $\begin{array}{l}\text { GP } \\
\text { GC }\end{array}$ & $\begin{array}{l}10,78 \\
18,05\end{array}$ & $\begin{array}{l}12,05 \\
19,20\end{array}$ & $\begin{array}{l}9,87 \\
5,73\end{array}$ & 0,0545 & 0,054 \\
\hline 3003 & $\begin{array}{l}\text { GP } \\
\text { GC }\end{array}$ & $\begin{array}{l}12,12 \\
16,51\end{array}$ & $\begin{array}{l}14,53 \\
18,40\end{array}$ & $\begin{array}{l}8,38 \\
7,81\end{array}$ & 0,0870 & 0,183 \\
\hline 4004 & $\begin{array}{l}\text { GP } \\
\text { GC }\end{array}$ & $\begin{array}{l}13,64 \\
18,70\end{array}$ & $\begin{array}{l}15,18 \\
19,60\end{array}$ & $\begin{array}{c}6,59 \\
18,93 \\
\end{array}$ & 0,0725 & 0,075 \\
\hline 6006 & $\begin{array}{l}\text { GP } \\
\text { GC }\end{array}$ & $\begin{array}{c}8,87 \\
10,78\end{array}$ & $\begin{array}{l}11,55 \\
12,05\end{array}$ & $\begin{array}{c}11,32 \\
9,87\end{array}$ & 0,4856 & 0,443 \\
\hline
\end{tabular}

Legenda: GC: grupo controle; GP: grupo pesquisa.

\section{Discussão}

Nesse estudo foi avaliado o perfil audiológico (limiar de frequências ultra-altas e ocorrência de emissões otoacústicas) de pais de sujeitos com deficiência auditiva de herança recessiva, para testar a hipótese de que eles poderiam apresentar discretas alterações em sua audição, não evidenciadas através de testes audiológicos convencionais. Tais discretas alterações poderiam decorrer do fato de que eles são heterozigotos em relação a mutações genéticas que, em homozigose, levaram à surdez de herança autossômica recessiva em seus filhos. 
Entretanto, quatro pais do grupo pesquisa na faixa etária de 50 a 60 anos (todos com a mutação do 35delG em heterozigose), apresentaram, de fato, perda de audição. Não se sabe se a perda de audição é devida completamente a fatores ambientais ou, ainda, se a presença do alelo causador da surdez em heterozigose poderia ser responsável pela perda de audição, tornando o sujeito mais susceptível à presbiacusia ou a fatores ambientais que prejudicam a audição. Não se pode descartar a influência dos fatores ambientais mesmo nos casos de perda de audição de origem genética ${ }^{19}$. Também é possível especular que alelos que causam surdez recessiva, em heterozigose, provocam, de fato, perdas auditivas, porém de grau mais leve do que as presentes em seus filhos homozigotos. Um número amostral maior poderia confirmar essa hipótese.

Três estudos ${ }^{20-22}$ encontraram diferenças significantes nos níveis de resposta para audiometria de altas frequências e emissões otoacústicas de sujeitos portadores e não-portadores da mutação 35delG em heterozigose (mutação mais frequente da Conexina 26).

Em relação às frequências ultra-altas, foi descartada a frequência de $9 \mathrm{kHz}$, por apresentar uma diferença estatisticamente significante (teste $t$ Student) de resposta entre as orelhas. Tal resultado pode ter ocorrido devido ao efeito da ordem em que foram apresentados os estímulos, primeiro na orelha direita e depois na orelha esquerda, de maneira que esta apresentou melhor sensibilidade às respostas.

Observou-se uma tendência dos melhores limiares audiométricos para o GC, no entanto, sem relevância estatística. Umestudo ${ }^{23}$ encontrou uma grande variabilidade dos limiares das frequências ultra-altas em análise inter e intrasujeitos com limiares auditivos dentro danormalidade. A grande variabilidade nos limiares tonais e o pequeno número de sujeitos das amostras sugerem a necessidade de estudos com maior número de participantes, para se garantir a precisão dos dados audiológicos.

Em relação às emissões otoacústicas - produto de distorção - foi encontrada uma diferença entre os limiares nos GP e GC, de modo que o GC apresentou maiores relações sinal/ruído (SNR) do que o GP, indicando uma melhor audição em relação aos pais de sujeitos com perda auditiva. Tais diferenças também não foram estatisticamente significantes, exceto para as frequências de 1001 e $1501 \mathrm{~Hz}$.
Alguns estudos avaliaram a audição em altas frequências ( 9 a 20kHz) em indivíduos com queixa de zumbido e audição normal nas frequências de 0,25 a $8 \mathrm{kHz}^{24-25}$. As autoras encontraram diferença significante entre os grupos para os limiares auditivos em altas frequências ( 9 a 20kHz), sugerindo ser este um instrumento apropriado na avaliação de alterações cocleares antes de aparecerem no audiograma. No presente estudo, a audiometria em altas frequências (9 a $20 \mathrm{kHz}$ ) não diferenciou os grupos avaliados, apenas os resultados obtidos nas EOAPD.

Um estudo $^{26}$ encontrou que sujeitos da população geral com limiares de frequências ultra-altas aumentados apresentaram diferença estatisticamente significante para as frequências f2 de $6348 \mathrm{~Hz}$ e na frequência de $1001 \mathrm{~Hz}$, sendo que a última é compatível com os achados deste estudo. A autora refere que tal resultado significa a confirmação de que a diminuição nos limiares das altas frequências interfere na amplitude das EOAPD. A literatura ${ }^{27-28}$ refere que pequenas alterações nas células ciliadas da cóclea podem influenciar a resposta das frequências mais baixas das emissões otoacústicas, que são geradas por uma região basal da cóclea. Tais resultados seriam altamente influenciados pelas frequências ultra-altas, fato que não foi observado neste presente estudo, já que não houve relação de significância em nenhuma das frequências ultra-altas. No entanto, tal resultado pode ser justificado pelo pequeno número da amostra de sujeitos e, desta forma, a necessidade de uma amostra maior em pesquisas posteriores faz-se necessária.

Estudos populacionais analisando os membros de famílias dos sujeitos com surdez por herança genética contribuem para o avanço do conhecimento no campo. Especificamente, encontrar indicadores que possibilitem a correlação entre o fenótipo (achados audiológicos) e genótipo causaria um grande impacto na prática clínica e no aconselhamento genético da surdez ${ }^{22}$.

\section{Conclusão}

Dentre os procedimentos adotados, a pesquisa das EOAPD demonstrou maior eficácia para detecção de diferenças entre os grupos, revelando maior tendência a comprometimento no grupo pesquisa. Observou-se também que há uma tendência de pais de indivíduos com surdez de herança autossômica recessiva apresentarem piores resultados nos testes audiológicos, verificada já nos limiares de 250 a $8000 \mathrm{~Hz}$ da audiometria convencional.

Agradecimentos: agradecemos à Fundação de Amparo à Pesquisa do Estado de São Paulo (FAPESP) pelo financiamento (Processo 2008/55498-5) e à Maria Teresa Balester de Mello Auricchio - Instituto de Biociências da USP, pelo apoio técnico. 


\section{Referências Bibliográficas}

1. Roush J, Holcomb MA, Roush PA, Escolar, ML. When hearing loss occurs with multiple disabilities. Semin Hear. 2004;25(4):333-45.

2. Van Camp G, Willems PJ, Smith RJ. Nonsyndromic hearing impairment: unparalleled heterogeneity. Am J Hum Genet. 1997;60:758-64.

3. Petersen MB, Willems PJ. Non-syndromic, autosomalrecessive deafness. Clin Genet. 2006;69:371-92.

4. Schrijver I. Hereditary non-syndromic sensorineural hearing loss. J Mol Diagn. 2004;6(4):275-84.

5. Friedman TB, Griffith AJ: Human nonsyndromic sensorineural deafness. Annu. Rev. Genomics Hum Genet. 2003;4:341-402.

6. Petersen MB. Non-syndromic autosomal-dominant deafness. Clin Genet. 2002;62:1-13.

7. Willems PJ. Mechanism of disease: genetic causes of hearing loss. N. Engl. J. Med. 2000;342(15):1101-9.

8. Kelsell DP, Dunlop J, Stevens HP, Lench NJ, Liang JN, Parry G, Mueller RF, Leigh IM. Connexin 26 mutations in hereditary non-syndromic sensorineural deafness. Nature. 1997:387:80-3.

9. Dahl E, Manthey D, Chen Y, Schwarz HJ, Chang YS, Lalley PA, Nicholson BJ, Willecke K. Molecular cloning and functional expression of mouse connexin-30, a gap junction gene highly expressed in adult brain and skin. J. Biol. Chem. 1996;271(30):17903-10.

10. Sabag AD, Dagan O, Avraham KB. Connexins in hearing loss: a comprehensive overview. J Basic Clin. Physiol. Pharmacol. 2005;16(2-3):101-16.

11. Carrasquillo MM., Zlotogora J, Barges S, Chakravarti A. Two different connexin 26 mutations in an inbred kindred segregating non-syndromic recessive deafness: implications for genetic studies in isolated populations. Hum. Molec. Genet. 1997;6:2163-72.

12. Batissoco AC, Abreu-Silva RS, Braga MCC, Lezirovitz K, Della-Rosa V, Tabith A, Otto PA, Mingroni-Netto RC. Prevalence of GJB2 (Connexin-26) and GJB6 (Connexin-30) mutations in a cohort of 300 Brazilian hearing-impaired individuals: implications for diagnosis and genetic counseling. Ear Hear. 2009;30(1):1-7.

13. Wilcox SA, Saunders K, Osborn AH, Arnold A, Wunderlich $\mathrm{J}$, Kelly T, et al. High frequency hearing loss correlated with mutations in the GJB2 gene. Hum. Genet. 2000;106:399-405.

14. Zelante L, Gasparini P, Estivill X, Melchionda S, D'Agruma L, Govea N, Mila M, Monica MD, Lutfi J, Shohat M, Mansfield E, Delgrosso K, Rappaport E, Surrey S, Fortina P. Connexin 26 mutations associated with the most common form of nonsyndromic neurosensory autosomal recessive deafness (DFNB1) in Mediterraneans. Hum. Mol. Genet. 1997;6:1605-9.

15. del Castillo FJ, Rodriguez-Ballesteros M, Alvarez A, Hutchin T, Leonardi E, de Oliveira CA, Azaiez H, Brownstein Z, Avenarius MR, Marlin S, Pandya A, Shahin H, Siemering KR, Weil D, Wuyts W, Aguirre LA, Martin Y, MorenoPelayo MA, Villamar M, Avraham KB, Dahl HHM, Kanaan M, Nance WE, Petit C, Smith RJH, Van Camp G, Sartorato EL, Murgia A, Moreno F, del Castillo I. A novel deletion involving the connexin-30 gene, del(GJB6-d13s1854), found in trans with mutations in the GJB2 gene (connexin26) in subjects with DFNB1 non-syndromic hearing impairment. J Med Genet. 2005;42:588-94.
16. Estivill X, Govea N, Barceló E, Badenas C, Romero E, Moral L et al. Familial progressive sensorineural deafness is mainly due to the mtDNA A1555G mutation and is enhanced by treatment of aminoglycosides. Am J Hum Genet. 1998;(62):27-35.

17. Davis H, Silverman SR. Auditory test hearing aids. In: Davis H, Silverman SR (ed.). Holt: Rinehart and Winston Hearing and Deafness; 1970.

18. Carvallo RMM, Koga MC, Carvalho M, Ishida IM. Limiares auditivos para altas freqüências em adultos sem queixa auditiva. Acta - ORL 2007;25(1):62-66.

19. Rabionet R, Gasparini P, Estivill X. Molecular genetics of hearing impairment due to mutations in gap junctions genes encoding beta connexins. Hum Mutat. 2000;16:190202.

20. Morell RJ, Kim HJ, Hood LJ, Goforth LG, Friderici K, Fisher R, Van Camp G, Berlin CI, Oddoux C, Ostrer H, Keats B, Friedman TB. Mutation in the connexin 26 gene (GJB2) among ashkenazi jews with nonsyndromic recessive deafness. N. Engl. J. Med. 1998;339:1500-5.

21. Engel-Yeger B, Zaaroura S, Zlotogora J, Shalev S, Hujeirat Y, Carrasquillo M, Barges S, Pratt $H$. The effects of a connexin 26 mutation - 35delG - on oto-acoustic emissions and brainstem evoked potentials: homozygotes and carriers. Hear Res. 2002;163:93-100.

22. Engel-Yeger B; Zaaroura S; Zlotogora J; Shalev S; Hujeirat Y; Carrasquillo M; Saleh B; Pratt H. Otoacoustic emissions and brainstem evoked potentials in compound carriers of connexin 26 mutations. Hear Res. 2003;175:14015.

23. Sahyeb DR, Costa Filho OA, Alvarenga KF. Audiometria de alta-frequência: estudo com indivíduos audiologicamente normais. Rev. Bras.Otorrinolaringolol. 2003;69(1):93-9.

24. Burguetti FAR, Peloggia AG, Carvallo RMM. Limiares de Audibilidade em Altas Freqüências em Indivíduos com Queixa de Zumbido. Arq. Otorrinolaringol. 2004;8(4):27783

25. Sanches SGG, Sanchez TG, Carvallo RMM. Influence of cochlear function on auditory temporal resolution in tinnitus patients. Audiol. Neurootol. 2010;15:273-81

26. Carvallo RMM. Audição em altas freqüências: repercussões no reconhecimento de fala no ruído e nas emissões otoacústicas. Tese de livre docência apresentada à Faculdade de Medicina da Universidade de São Paulo; 2002.

27. Arnold DJ, Lonsbury MBL, Martin GK. High frequency hearing influences lower - frequency distortion - product otoacoustic emissions. Arch. Otolaryngol. Head Neck Surg. 1999;125:215-22.

28. Groh D, Pelanova J, Jilek M, Popelar J, Kabelka Z, Syka J. Changes in otoacoustic emissions and high-frequency hearing thresholds in children and adolescents Hear Res. 2006;212:90-8. 